http://jmscr.igmpublication.org/home/ ISSN (e)-2347-176x ISSN (p) 2455-0450

crossref DOI: https://dx.doi.org/10.18535/jmscr/v8i3.09

\title{
Awareness, Knowledge and Perceived Barriers to Male Involvement in Safe Motherhood among Men in Ife Central Local Government Area, South West, Nigeria
}

\author{
Authors \\ Ogidan Oluwakemi Christie ${ }^{1 *}$, Oke Rebecca Oluwaseun ${ }^{2}$
}

Department of Nursing Science, College of Medicine, Ekiti State University, Ado-Ekiti, Ekiti-State, Nigeria

*Corresponding Author

Ogidan O.C.

Lecturer II Department of Nursing Science, College of Medicine, Ekiti State University, Ado-Ekiti, Ekiti-State, Nigeria

\begin{abstract}
Objectives: Assessed the awareness, knowledge of safe motherhood and the barriers to male involvement in safe motherhood.

Study Design: the study is descriptive cross sectional research design in which 60 men from the participating 3 wards in Ife central local government, Osun state were selected using muiti-stage sampling method. Data were obtained using a self-developed, pretested questionnaire, sorted and analysed using SPSS version 20. The results were presented using frequency tables and pie charts

Results: The study revealed that well below average (16.7\%) of the respondents heard about safe motherhood less than 10 years ago and only 16.7\% gave correct description of safe motherhood. Majority of the respondents have fair knowledge of the components of safe motherhood and danger signs of pregnancy. Also, there is significant relationship between the educational status of men and their knowledge of components of safe motherhood. Major barriers identified are lack of access to accurate information about safe motherhood (86.7\%), societal and religion disapproval of open discussion of sexual matters (85\%) and sexual and reproductive health services that is exclusively focused on women (73.3\%).

Conclusion: The awareness of safe motherhood is poor, the men identified the danger signs of pregnancy and component of safe motherhood, this could impact male to take immediate action at the sight of the danger signs in their partners. However, there is need to overcome the barriers identified in order to have male involved in safe motherhood.

Keywords: Awareness, Knowledge, Barriers, Safe motherhood, Male involvement, Men.
\end{abstract}

\section{Introduction}

Nigeria is the most populous country in Africa and $7^{\text {th }}$ most populated country in the world, with more than 200 million people accounting for $2.35 \%$ of the entire earth's population (National Bureau of statistics, 2019). It has also constituted about 268\% increase between 1960 and year 2012 (world population prospects, 2019 revision). Additionally, the country accounts for a high percentage of infant and maternal mortality rate globally; A joint report on trends in maternal mortality: 1990 to 2015 by WHO, UNICEF, 
WORLD Bank and United Nations Population Fund estimates that Nigeria has approximately 58,000 maternal deaths, accounting for $19 \%$ globally. It further shows that at least 814 women die in every 100,000 live births from preventable causes related to pregnancy and childbirth (World Health Organization: WHO, 2018). These observations make the country a major focus of all initiatives directed at reducing maternal and infant morbidity and mortality.

The global Safe Motherhood Initiative (SMI) was launched in 1987 in Nairobi, Kenya to raise awareness about the scope and consequences of poor maternal health and to mobilize action to address the high rates of deaths and complications of pregnancy and childbirths. To reduce maternal mortality and morbidity, interventions had been ongoing in the areas of implementation of Safe Motherhood Initiatives and the Sustainable Development Goals (SDGs).

Despite the interventions, studies continue to show that existing strategies to save mothers' lives had been less successful especially as Nigeria's maternal mortality profile still remains unacceptably high (Abimbola et al., 2012; Kana, Doctor, Peleteiro, Lunet \& Barros,2015). This may be due to less emphasis placed on the adverse maternal outcomes due to social factors that surround decision making at home in obstetric care (Ganle et.al ., 2017). Many pregnant women are dying in Nigeria not because of pregnancy as a biological function, but because of the neglect they suffer in the management of the event particularly from home. Eneh \& Nkamnebe (2011) observed that women in Sub-Saharan Africa are in a disadvantaged position in terms of decision making at home and they are not in control of their sexuality. According to Mojekwu and Ibekwe (2012) Safe Motherhood Initiative have not been successful in reducing maternal mortality in Nigeria probably because interventions are centered around the women who are rather passive in decision making on reproductive health in an average African family setting.
It has been suggested that, in addition to biomedical interventions in the strengthening of health care services, improving awareness of obstetric complications among members of a pregnant woman's immediate and wider social network especially among men is an important step in improving her chances of survival (Ensor et. al., 2014). It is now increasingly being recognized that the actions required to achieve improvements in reproductive health outcomes in general, and maternal health in particular, should involve communities in the process and encourage men's active participation (Ensor et.al., 2014).

Male involvement in reproductive health is a key factor in the adoption and sustained safe motherhood in Nigeria where men often dominate decision (Nwakwuo and Oshonwoh, 2012). Very few studies have targeted men knowledge of safe motherhood to fulfilling their roles in safe motherhood in rural Nigerian communities (Ogunyigbe, 2002; Feyisetan, 2000). This study is therefore designed to examine critically the awareness, knowledge and perceived barriers to male involvement in safe motherhood among men in Ife central local government area, South-West, Nigeria with respect to their understanding of components of safe motherhood and danger signs of pregnancy.

\section{Methodology}

Study Design: A descriptive cross sectional research design was utilized in this study to assess the awareness, knowledge and perceived barriers to male involvement in safe motherhood among men in Ife Central Local Government Area, South West, Nigeria.

Sample and Sampling Technique: The study was conducted in Ile-Ife town, Ife Central Local Government Area in Osun State, Nigeria. Ile-Ife has 11 traditional wards. According to the National Population Commission (2006), Ife Central Local Government has a population of 88,403 men and 78,801 women with an estimated number of 1 married and 1 single man per household. 
Multistage sampling technique was adopted in selecting the traditional wards, streets and households from where married and single men were selected to constitute the sample for the study. Out of the 11 traditional wards in the town of Ile-Ife, 3 wards were randomly selected: Moore/Ojoja ward, Iremo ward I, Il are ward III in Ife central local government, Ile-Ife. A Street on each of the wards was selected using simple random sampling. The first ten households were selected purposively to be the source of 10 married men and 10 Single men who are not below the age of 18 years to constitute the 60 respondents.

\section{Data Collection}

Data for the study were collected using pre-tested structured, self-developed questionnaires which were given to the respondents on a one on one basis and same were collected immediately to prevent misplacement. The respondents were to provide information on their awareness, knowledge and perceived barriers to male involvement in safe motherhood. The questionnaire consists of four sections; addressing the demographical data and each of the objectives of the study. The instrument's face and content validity was ascertained.

\section{Ethical Consideration}

Permission for study was obtained from respective ward heads. Participants were required to give a verbal consent to participate in the study. The reluctance of the respondents to discuss potentially sensitive sexual matters was eliminated by assuring the participants of the confidentiality of the information provided which is purely for research purpose. Also the anonymity of the respondents was assured.

\section{Data Analysis}

The data collected was analyzed using Statistical Package for Social Sciences (SPSS) version 16. The result was presented using descriptive statistical methods such as frequency tables and bar chart.

\section{Result}

\section{Awareness of safe motherhood}

Table 1: Distribution of respondents by Awareness of Safe Motherhood

\begin{tabular}{|l|c|c|}
\hline & $\begin{array}{c}\text { Frequency } \\
(\mathbf{N}=\mathbf{6 0})\end{array}$ & Percent= 100 \\
\hline When first heard about safe motherhood (in years) & & \\
\hline no response & 33 & 55.0 \\
\hline Less than 10 & 10 & 16.7 \\
\hline 10 to 20 & 9 & 15.0 \\
\hline 20 to 30 & 4 & 6.7 \\
\hline 30 to 40 & 4 & 6.7 \\
\hline Source of information & 20 & 33.3 \\
\hline no response & 10 & 16.7 \\
\hline Nurses & 4 & 6.7 \\
\hline Doctors & 15 & 25.0 \\
\hline mass media & 6 & 10.0 \\
\hline Friends & 5 & 8.3 \\
\hline Others & & \\
\hline Where information was first received & 6 & 10.0 \\
\hline No response & 12 & 20.0 \\
\hline Nurses & 3 & 5.0 \\
\hline Doctors & 30 & 50.0 \\
\hline mass media & 5 & 8.3 \\
\hline Friends & 4 & 6.7 \\
\hline Others & & \\
\hline Description of safe motherhood & 50 & 83.3 \\
\hline Not correct & 10. & 16.7 \\
\hline Correct & & \\
\hline
\end{tabular}


Well below average $(16.7 \%)$ of the respondents heard about safe motherhood less than 10 years ago, less than this $(15.0 \%)$ heard about it between 10 and 20 years ago, while fairly above average of the respondents gave no responses to the item on when they first heard about safe motherhood.
Mass media was the major source of information (25.0\%), while $16.7 \%$ heard from nurses. Majority of the respondents $(65 \%)$ could not correctly describe safe motherhood, only $16.7 \%$ gave correct description.

\section{Knowledge of components of safe motherhood}

Table 2 Distribution of respondents by knowledge of different components of SM

\begin{tabular}{|l|l|c|c|}
\hline & Components of safe motherhood & $\begin{array}{c}\text { Frequency of respondent } \\
\text { with correct knowledge (\%) }\end{array}$ & $\begin{array}{c}\text { Frequency of respondents with } \\
\text { incorrect knowledge (\%) }\end{array}$ \\
\hline 1 & Community education on safe motherhood & $56(93)$ & $4(7)$ \\
\hline 2 & Reproductive health counseling & $53(88)$ & $7(12)$ \\
\hline 3 & Prenatal care & $56(93)$ & $4(7)$ \\
\hline 4 & Promotion of maternal nutrition & $56(93)$ & $4(7)$ \\
\hline 5 & Skilled assistance during childbirth & $56(93)$ & $4(7)$ \\
\hline 6 & Care for obstetric complications & $56(93)$ & $4(7)$ \\
\hline 7 & Management of obstetric emergencies & $53(88)$ & $7(! 2)$ \\
\hline 8 & Postpartum care & $53(88)$ & $7(12)$ \\
\hline 9 & Management of abortion complications & $43(72)$ & $21(28)$ \\
\hline 10 & Post abortion care & $39(65)$ & $23(35)$ \\
\hline 11 & $\begin{array}{l}\text { Safe services for the termination of pregnancy } \\
\text { (where abortion is not against the law) }\end{array}$ & $37(62)$ & $8(13)$ \\
\hline 12 & $\begin{array}{l}\text { Family planning counseling, information and } \\
\text { services }\end{array}$ & $52(87)$ & $6(10)$ \\
\hline 13 & Reproductive health education & $48(80)$ \\
\hline 14 & Reproductive health services for adolescents. & $54(90)$ & $39(68)$ \\
\hline 15 & School Health services & $12(20)$ & \\
\hline
\end{tabular}

The table above show that majority of respondents (80\% and 68\%) identified items 14 and 15 as part of components which are actually not while only
65 and $62 \%$ of the respondent have the knowledge of the components of items 10 and 11.

Figure I: Knowledge of components of safe motherhood.

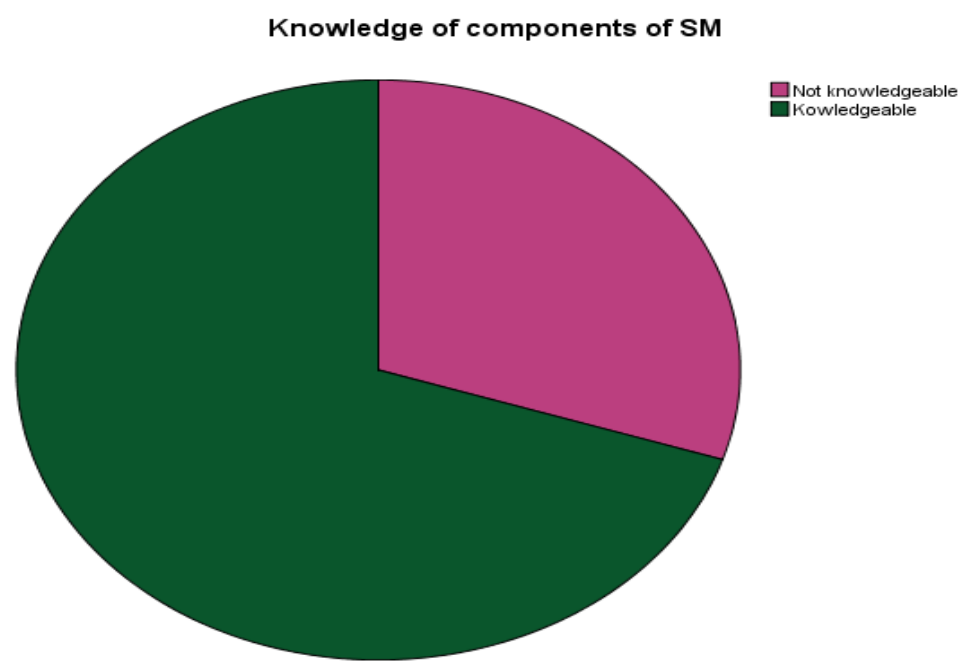

Above figure shows the number of respondents that has good knowledge of components of safe motherhood based on number of respondents that score below or above $70 \%$ as it relates to life matter. 
Knowledge of danger signs of pregnancy

Table 4.4.1: Distribution of respondents by the knowledge of different danger signs of pregnancy

\begin{tabular}{|l|l|c|c|}
\hline & Danger signs of pregnancy & $\begin{array}{c}\text { Frequency of } \\
\text { respondent with } \\
\text { correct knowledge } \\
\text { (\%) }\end{array}$ & $\begin{array}{c}\text { Frequency of } \\
\text { respondents } \\
\text { with incorrect } \\
\text { knowledge(\%) }\end{array}$ \\
\hline 1 & Swelling of woman's feet and hands & $41(68)$ & $19(32)$ \\
\hline 2 & Severe headache or fits & $44(73)$ & $16(27)$ \\
\hline 3 & Fever & $41(68)$ & $19(32)$ \\
\hline 4 & Smelly vaginal discharge & $38(63)$ & $22(37)$ \\
\hline 5 & Vaginal bleeding before labour & $40(67)$ & $20(33)$ \\
\hline 6 & Any part of the baby showing other than the head & $44(73)$ & $16(27)$ \\
\hline 7 & Heavy bleeding during or after labour & $54(90)$ & $6(10)$ \\
\hline 8 & $\begin{array}{l}\text { Labour lasting more than one nightfall to one sunrise or vice } \\
\text { versa. }\end{array}$ & $48(80)$ & $12(20)$ \\
\hline 9 & Constipation & $18(30)$ & $42(70)$ \\
\hline 10 & Frequent Urination & $31(52)$ & $29(48)$ \\
\hline
\end{tabular}

The table above revealed that less than $70 \%$ of the respondents were able to identify items $1,3,4$ and 5 as danger signs of pregnancy while only $30 \%$ and $52 \%$ of the respondents disagree with item numbers 9 and 10 respectively as danger signs of pregnancy.

\section{Hypotheses testing}

Hypothesis I: There is no significant relationship between the educational status of men in Ife central local government Ile-Ife and their knowledge of components of safe motherhood

\begin{tabular}{|l|c|c|c|c|c|c|}
\hline Educational status & \multicolumn{2}{|c|}{ Knowledge of components of SM } & Total & $\chi^{2}$ & Df & P \\
\hline & $\begin{array}{c}\text { Not } \\
\text { knowledgeable }\end{array}$ & $\begin{array}{c}\text { Knowledgeable } \\
\text { Below secondary }\end{array}$ & 9 & & & \\
\\
\hline Secondary & 9 & 9 & 13 & \multirow{2}{*}{5.715} & \multirow{2}{*}{3} & \multirow{2}{*}{0.126} \\
\hline Tertiary & 5 & 24 & 29 & & & \\
\hline
\end{tabular}

P-value (0.126) is less than the significance level $(\mathrm{p}<0.05), \mathrm{H}_{0}$ is therefore rejected, and the hypothesis is therefore re-stated as 'there is a significant relationship between the educational status of men in Ife central local government, IleIfe and their knowledge of components of safe motherhood

\section{Discussion of Findings}

Demographic distribution of the respondents' shows that majority of the respondents were in the age range of 21-35 years and belong to Yoruba ethnic group. A good percentage had postsecondary education and in monogamous family setting. A larger percentage of the respondents married between the ages of 26-30. Majority of the respondents desired to have 5 children which is in conformity with the fertility rate in Nigeria which is 5.8 (Multiple indicator cluster survey, 2016) and fewer number of the respondents had one dead child

Findings on awareness of respondents about safe motherhood reveals that greater percentage of the respondents have heard about safe motherhood not less than 10 years ago but only very few (10\% precisely) can explain what safe motherhood is, this can be said to be partially due to the source of the information as majority stated that mass media was the major source of information in which mode of interaction may be low while very well below average gain information directly from health care workers. This is in support of the work carried out by August, Pembe, Mpembeni, Axemo 
and Darj (2015) which revealed that men have low knowledge of obstetric danger signs.

Assessment of respondents' knowledge of components of safe motherhood shows that majority identified what are not components of safe motherhood as components. On a general note, majority of the respondents are knowledgeable about the components but fairly below average have low knowledge of components of safe motherhood. This findings corroborates what other studies reported in their findings (Atuahene, Arde-Acquah, Atuahene, Adjuik and Ganle, 2017; Kura, Vince and Crouchchivers,2013) that most of the men correctly recognized the importance of antenatal care, family planning and skilled delivery care.

Investigation into respondents knowledge of danger signs of pregnancy shows that a larger percentage are knowledgeable of the danger signs of pregnancy. This may be due to the fact that a larger percentage of the respondents has up to post-secondary school education. However more work still have to be done as fairly below average of the respondents have poor knowledge of these danger signs and a study carried out by Sekoni and Owoaje (2014) show that above two-third of men had poor knowledge about danger signs in pregnancy. This has greater implications on mother and child health.

\section{Conclusion}

In conclusion, the results of the study shows that men are fairly knowledgeable about safe motherhood and their roles in it, they are also fairly involved in safe motherhood. However men alone are not to be blamed for the lack of adequate knowledge and involvement in safe motherhood as there are certain factors that serve as barriers to their involvement which are beyond men control to eliminate these barriers.

Conflict of Interest: No conflict of interest was declared by any of the authors.

Ethical Approval: Permission for study was obtained from respective ward heads. Participants were required to give a verbal consent to participate in the study

Funding Sources: The study was fully funded by the authors.

\section{References}

1. Abimbola, S., Okoli, U., Olubanjo, O., Abdullahi, M. J., \& Pate, M.A. (2012). The midwives service scheme in Nigeria. PLOS Medicine, 9(5), 541.

2. August F., Pembe A.B., Mpembeni R, Darj E (2015) Men's Knowledge of Obstetric Danger Signs, Birth Preparedness and Complication Readiness in Rural Tanzania. PLoS ONE10(5): e0125978.doi:10.1371/journal.pone.01259 78.

3. Atuahene M.D., Arde-Acquah S., Atuahene N.F., Adjuik M. and Ganle J.K.,(2017) Inclusion of men in maternal and safe motherhood services in inner-city communities in Ghana: evidence from a descriptive cross-sectional survey.BioMed Central Pregnancy and childbirth.17:419 doi: 10.1186/s12884-017-1590-3.

4. Eneh O.C. and Nkamnebe A. D. (2011) Gender gap and sustainable development in Nigeria:Issues and strategic choices. Asian journal of Rural Development Vol1(1) 41-53.

5. Ensor T., Green C., Quigley P., Badru A.R., Kaluba D. \& Kureya T. (2014) Mobilizing communities to improve maternal health:results of an intervention in rural Zambia. Bulletin of the world Health Organization 92: 51-59.

6. Feyisetan B.J.(2000) Spousal communication and contraceptive use among the Yoruba of Nigeria.Population Research and Policy vol.19:29-45.

7. Ganle J. K., Obeng B., Segbefia A. Y., Mwinyuri V., Yeboah J.Y. \& Baatiema L. (2017)Hoe intra-familial decision-making affects women's access to, and use of maternal healthcare services in Ghana: a 
qualitative study. BMC pregnancy and childbirth, 15: 173.

8. Kana, M.A., Doctor, H. V. Peleteiro, B., Lunet, N., \& Barros, H. (2015) Maternal and child health interventions in Nigeria: A systematic review of published studies from 1990 to 2014.BNC public Health, 15(1), 334.

9. Kura S, Vince J, and Crouch-chivers P. (2013) Male involvement in sexual and reproductive health in the Mendi district, southern highlands province of papua New Guinea: a descriptive study. Reprod Health. 10(46)1-10.

10. Mojekwu J.N.\& Ibekwe U. (2012) Maternal mortality in Nigeria: Examination of Intervention Methods. International Journal of Humanities and social science Vol 2(20).

11. Multiple indicator cluster Survey(MICS) (2016)Demographic Statistics bulletinnational bureau of statistics.

12. National Bureau of statistics (2019) Nigeria population 2019 retrieved from http://worldpopulationreview.com/countrie s/Nigeria

13. National Population Commssion (NPC) (2006). The 2006 Population Census of Nigeria. Analytical Report.

14. Nwakwuo G.C. \& Oshonwoh F.E. (2012) Assessment of the level of Male involvement in Safe Motherhood in southern Nigeria.Journal of community Health 38:349-356.

15. Ogunjuyigbe P.O (2002) Men's influence on desired family size and couples reproductive decision-making in Nigeria. Niger J Soc.
16. Sekoni O.O. and Owoaje E.T. (2014) Male knowledge of Danger signs of Obstetric complications in an urban city in south west, Nigeria. Annals of Ibadan Postgraduate Medicine 12(2): 89-95.

17. World Population Prospects (2019 revision) United nations population estimates and projection retrieved from http://2019worldpopulationreview.com/co untries/Nigeria.

18. World Health Organization (2018) A joint report trends in Maternal Mortality: 1990 to 2015 by WHO, Unicef, world bank and united population fund. retrieved from http://WHOafrica/Countries/Nigeria/News. 